(RESEARCH ARTICLE)

\title{
Photopolymerization devises light intensity relation with physical translucid barriers use
}

\author{
Fernando Mauricio Villalta Mendoza ${ }^{1,}{ }^{*}$, Jhonny Leonel Gonzalez Ortega ${ }^{1}$, Yulissa Raquel Abad Salinas 2 \\ ${ }^{1}$ Bachelor in General Dentistry Faculty of Dentistry, University of Cuenca. \\ ${ }^{2}$ Specialist in oral rehabilitation Associate Professor of Faculty of Dentistry, University of Cuenca Faculty of Dentistry of \\ the University of Cuenca.
}

Publication history: Received on 11 October 2020; revised on 20 October 2020; accepted on 23 October 2020

Article DOI: https://doi.org/10.30574/wjarr.2020.8.1.0382

\begin{abstract}
Nowadays, the use of halogen or light emission diode (LED) devices in dental attention is constant for almost any oral treatment. The need of providing an adequate light intensity for a correct photopolymerization of the resinous materials is critical. Likewise, it is important to consider the biosecurity norms for avoiding cross-contamination by residues likely to be accumulated at the top of the light guide in contact with oral cavity fluids. Therefore, the use of translucid barriers at the top of the light guide is imperative to protect the health of the patient while providing a correct polymerization of the resinous materials. The present study analyzes the effect of using four translucid barriers in the light intensity of three dental lamps commercially available. The tested barriers are two of commercial availability, and two conventional plastic wraps. Results indicate a significant reduction of light intensity without affecting the requirements for a correct photopolymerization with any barrier. Differences among barriers points out a conventional plastic wrap as more suitable than commercially available barriers, considering only light intensity provided.
\end{abstract}

Keywords: Light intensity; Sleeves; Light curing; Barriers

\section{Introduction}

Up to date, the use of resinous materials has increased drastically in general dentistry consult due to the aesthetic and functional advantages of these materials. Restorations with composed resins needs the light emitted by photo polymerization devices as physical means to be activated [1], [2].This is given due to the presence of traditional photoinitiators in its composition such as canforquinone [3] or other alternatives as Lucirin TPO or Ivoceri, among others [1].

The halogen and light-emitting diode (LED) lamps are common types of light devices, with LED as the most used due to its narrow wavelength with lower heat generation and no necessity for ventilation, representing lower costs. LED devices are classified into three generations according to their radiation. The first generation presents a range from 100 to $280 \mathrm{~mW}^{*} \mathrm{~cm}^{-2}$, requiring long time exposures (around 60 seconds). The second-generation produce a wavelength between 410 and 470 nanometers, presenting difficulties for the activation of alternative photo indicators. Finally, the third generation LED devices surged due to these limitations, presenting a better functioning thanks to the wavelengths between 380 to $500 \mathrm{~nm}$, a combination of blue and violet light that allows the activations of both traditional and alternative photo indicators [4]-[9].

The correct photopolymerization of these materials depends on several factors related to the lamp and its use, such as light intensity $\left(\mathrm{mW}^{*} \mathrm{~cm}^{-2}\right)$, exposure time, heat produced by the device, distance, and angle between the light and the resinous material. In the same way, we found biomaterial dependent factors as tone of resinous material, type of fill,

\footnotetext{
* Corresponding author: Fernando Mauricio Villalta Mendoza

Bachelor in General Dentistry Faculty of Dentistry, University of Cuenca.
} 
quantity of photo indicator in the material, and its thickness [3]. Rueggeberg et al., [10] and Martin et al., [11] described that the minimum intensity needed for the activation of a compound resin with a thickness of $2 \mathrm{~mm}$ must be 400 $\mathrm{mW}^{*} \mathrm{~cm}^{-2}$ with an exposure time of 60 seconds. The decrease in light intensity alters the mechanical properties of the material, allowing the creation of marginal micro filtrations. The low depth of photopolymerization entails to the degradation of the material with massive fractures, discoloration of the restoration, and post-operatory sensibility [12].

The presence of dental materials residues at the active extreme of the light guide of the lamp prevents the correct light supply, reducing the emitted intensity [13]. The presence of these residues in contact with oral fluids represents a risk factor of cross-contamination. The Center for Diseases Control (CDC) has categorized the photopolymerization elements as semi-critic due to its frequent relation with oral tissues and indicates that it has to be submitted to disinfection biosecurity norms [14]-[17]. There exist four recommended ways to obtain a suitable biosecurity with the use of photo activators devices:

Cold disinfection with ethanol solution at $70 \%$ or glutaraldehyde at $2 \%$ [18], [19]. The contact between the light guide and the disinfectant solution has to be a minimum of ten minutes to guarantee the viricide and sporicidal action. However, the glutaraldehyde solutions can reduce the light transmission or damage the fibers of the light guide [10].

The use of autoclavable fibers sterilized with distillate water at $134{ }^{\circ} \mathrm{C}$ for 20 minutes. In the same way, the autoclave use can reduce the light transmission capacity by $50 \%$ after three autoclave cycles due to the accumulation of mineral residues on the top of the guide light [18]-[20].

Use of plastic fibers pre-sterilized [18], [19].

Use of disposable translucid physical barriers [18]-[20].

This last option is recommended to avoid the cross-contamination and the dispose of materials waste at the top of the optic fiber. The used barriers can be of different materials as low-density polyethylene (LDP) or polypropylene (PP), which compounds different conventional plastic wrappings [14], [18]-[22]. Therefore, the main goal of this article is to analyze the relation of light intensity with the use of different translucid barriers in photo curating lamps.

\section{Material and methods}

The present research is of type exploratory - descriptive, in which the variability of light intensity from three photopolymerization devices were compared with the use of four translucid barriers. The light devices analyzed were: Bluephase N (Ivoclar-Vivadent, Schaan, Liechtenstein) (BN), Elipar DeepCure-L (3M ESPE, St Paul, Minnesota, USA) (EDC), and Maxima RU12000 (Henry Schein INC, Melville, New York, USA) (MRU). The selected barriers were two of commercial availability: Pent Type Curing Light Sleeve 123 (PremiumPlus, Brooklin, New York, USA) (PTCLS) and Plasdent Light Guide Sleeves PS 4500 (Perio Support, Novi, Michigan, USA) (PLGS); and two conventional plastic wraps: Strech (Consultplast, Cuenca, Ecuador) (S) and Plastic Wrap (Diafano, Cuenca, Ecuador) (PW). The light intensity was assessed with a dental radiometer Bluephase meter II (Ivoclar-Vivadent). Measures were done after established the diameter of the light guide for each device through the configuration of the dental radiometer and the integrated stencil in its back.

Before measures, each light guide top was disinfected with methyl alcohol at $70 \%$ and removed any kind of residue present in it, also, a maximum battery charge was considered with a continuous light output.

Techniques of descriptive and analytic statistics were used to determine the distribution of light intensity among the replicates and test groups. Also, a one-way analysis of variance (one-way ANOVA) and post-hoc Tukey test was developed to determine differences among lamps and test groups. All tests were developed in the software $\mathrm{R}$ and its interface R-Studio with a significance of $5 \%$.

\section{Results}

\subsection{Light intensity distributions}

The registered values of light intensity presented a no normal distribution for each analysis group. The lamps presented intensities that differ significantly among the brands selected for this study. However, all lamps presented light intensities above the recommended value for the photo-curate process. Table 1 indicates the distribution of light 
intensity values obtained for each analysis group, as well as the significance recorded from the Shapiro-Wilk normality test.

Table 1 Light intensity values distribution and normality test significance.

\begin{tabular}{|c|c|c|c|c|c|c|c|c|}
\hline Group & Lamp & $\mathbf{P}$ & Minimum & Q1 & Median & Mean & Q3 & Maximum \\
\hline \multirow{3}{*}{\begin{tabular}{l}
$\overline{0}$ \\
\multirow{3}{*}{} \\
0 \\
0
\end{tabular}} & 1 & 8,54E-06 & 750 & 750 & 750 & 753 & 750 & 770 \\
\hline & 2 & $4,67 \mathrm{E}-06$ & 1170 & 1180 & 1180 & 1178 & 1180 & 1180 \\
\hline & 3 & 0,01228 & 1470 & 1472 & 1480 & 1478 & 1480 & 1490 \\
\hline \multirow{3}{*}{ 岂 } & 1 & 0,03586 & 700 & 710 & 710 & 711 & 717,5 & 720 \\
\hline & 2 & 0,01541 & 1020 & 1020 & 1030 & 1027 & 1030 & 1040 \\
\hline & 3 & 0,001426 & 1430 & 1430 & 1430 & 1436 & 1440 & 1450 \\
\hline \multirow{3}{*}{ S } & 1 & 0,01541 & 710 & 710 & 720 & 717 & 720 & 730 \\
\hline & 2 & $4,71 \mathrm{E}-05$ & 1090 & 1092 & 1100 & 1097 & 1100 & 1100 \\
\hline & 3 & 0,03586 & 1420 & 1422 & 1430 & 1429 & 1430 & 1440 \\
\hline \multirow{3}{*}{ us } & 1 & 0,0001687 & 710 & 710 & 710 & 714 & 720 & 720 \\
\hline & 2 & 0,02195 & 1070 & 1080 & 1080 & 1080 & 1080 & 1090 \\
\hline & 3 & 0,004219 & 1430 & 1432 & 1445 & 1442 & 1450 & 1450 \\
\hline \multirow{3}{*}{3} & 1 & 0,00128 & 720 & 720 & 735 & 731 & 740 & 740 \\
\hline & 2 & 4,71E-05 & 1100 & 1100 & 1100 & 1103 & 1108 & 1110 \\
\hline & 3 & 0,00601 & 1450 & 1450 & 1460 & 1460 & 1470 & 1470 \\
\hline
\end{tabular}

Lamp: Bluephase N (1), Elipar DeepCure (2), Máxima RU12000 (3).

Groups: Control, Pent Type Curing Light Sleeve 123 (PTCLS), Plasdent Light Guide Sleeves PS 4500 (PLGS), Strech (S), and Plastic Wrap (PW).

\subsection{Differences between groups and lamps}

Significant differences of light intensity among all cover groups were determined. The Tukey post-hoc analysis allowed to determine to which group can be attributed such differences. Control groups were registered with values about 750 , 1180, and $1480 \mathrm{~mW}^{*} \mathrm{~cm}^{-2}$ for lamps one, two, and three, respectively as observed in Figures one to three. This group represent the main significant differences compared to each barrier group $(\mathrm{p}<0.05)$ as indicated in table two to four.

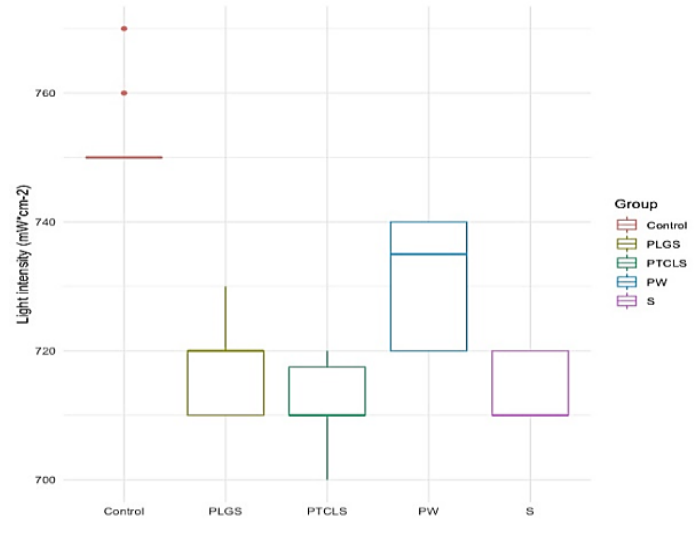

Figure 1 Groups boxplot distribution for lamp 1 


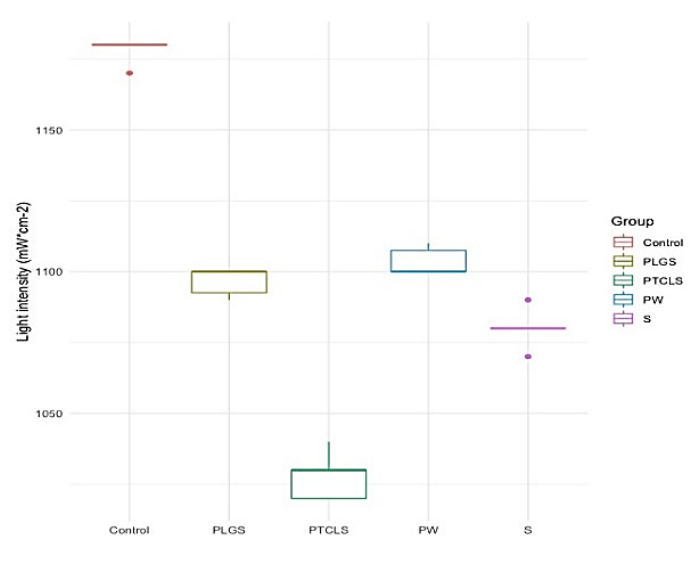

Figure 2 Groups boxplot distribution for lamp 2

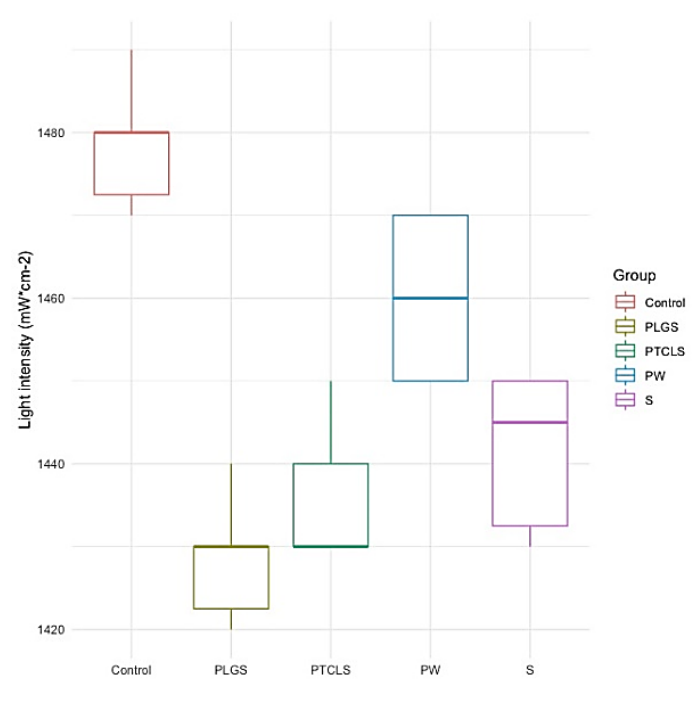

Figure 3 Groups boxplot distribution for lamp 3

Table 2 Post-Hoc group comparison for lamp one.

\begin{tabular}{|l|l|l|l|l|}
\hline Groups & Differences & Lower & Upper & $\boldsymbol{P}$ \\
\hline PTCLS - Control & -41 & -51.6654 & -30.33547 & 0.0000 \\
\hline PLGS - Control & -49 & -59.6654 & -38.33457 & 0.0000 \\
\hline S - Control & -35 & -45.6654 & -24.33457 & 0.0000 \\
\hline PW - Control & -17 & -27.6654 & -6.33457 & 0.0004 \\
\hline PLGS - PTCLS & -8 & -18.6654 & 2.66543 & 0.2250 \\
\hline S - PTCLS & 6 & -4.6654 & 16.66543 & 0.5061 \\
\hline PW - PTCLS & 24 & 13.3345 & 34.66543 & 0.0000 \\
\hline S - PLGS & 14 & 3.3345 & 24.66543 & 0.0046 \\
\hline PW - PLGS & 32 & 21.3345 & 42.66543 & 0.0000 \\
\hline PW - S & 18 & 7.3345 & 28.66543 & 0.0001 \\
\hline
\end{tabular}


Table 3 Post-Hoc group comparison for lamp two.

\begin{tabular}{|l|l|l|l|l|}
\hline Groups & Differences & Lower & Upper & $\boldsymbol{P}$ \\
\hline PTCLS - Control & -154 & -160.6165 & -147.3834 & 0.0000 \\
\hline PLGS - Control & -81 & -87.6165 & -74.38 & 0.0000 \\
\hline S - Control & -98 & -104.6165 & -91.3834 & 0.0000 \\
\hline PW - Control & -75 & -81.6165 & -68.3834 & 0.0000 \\
\hline PLGS - PTCLS & 73 & 66.3834 & 79.6165 & 0.0000 \\
\hline S - PTCLS & 56 & 49.3834 & 62.6165 & 0.0000 \\
\hline PW - PTCLS & 79 & 72.3834 & 85.6165 & 0.0000 \\
\hline S - PLGS & -17 & -23.6165 & -10.3834 & 0.0000 \\
\hline PW - PLGS & 6 & -0.6165 & 12.6165 & 0.0920 \\
\hline PW - S & 23 & 16.3834 & 29.6165 & 0.0000 \\
\hline
\end{tabular}

Table 4 Post-Hoc group comparison for lamp three.

\begin{tabular}{|l|l|l|l|l|}
\hline Groups & Differences & Lower & Upper & $\boldsymbol{P}$ \\
\hline PTCLS - Control & -42 & -51.3571 & -32.6428 & 0.0000 \\
\hline PLGS - Control & -36 & -45.3571 & -26.6428 & 0.0000 \\
\hline S - Control & -39 & -48.3571 & -29.6428 & 0.0000 \\
\hline PW - Control & -22 & -31.3571 & -12.6428 & 0.0000 \\
\hline PLGS - PTCLS & 6 & -3.3571 & 15.3571 & 0.3739 \\
\hline S - PTCLS & 3 & -6.3571 & 12.3571 & 0.8911 \\
\hline PW - PTCLS & 20 & 10.6428 & 29.3571 & 0.0000 \\
\hline S - PLGS & -3 & -12.3571 & 6.3571 & 0.8911 \\
\hline PW - PLGS & 14 & 4.6428 & 23.3571 & 0.0009 \\
\hline PW - S & 17 & 7.6428 & 26.3571 & 0.0000 \\
\hline
\end{tabular}

Groups PTCLS, PLGS, and S for lamp one presented the lower values with PW as the higher, representing the next main significant differences. Similar results were obtained for lamp two, where the barrier group PTCLS showed the lower light intensity with a median about $1020 \mathrm{~mW}^{*} \mathrm{~cm}^{-2}$ and the barrier group PW with the higher $\left(1100 \mathrm{~mW}^{*} \mathrm{~cm}^{-2}\right)$. Finally, the lower values for lamp three were presented in groups PTLCS and PLGS $\left(1430 \mathrm{~mW}^{*} \mathrm{~cm}^{-2}\right)$, while PW presented the higher $\left(1460 \mathrm{~mW}^{*} \mathrm{~cm}^{-2}\right)$.

\section{Discussion}

Nowadays the importance of accomplishing with adequate biosecurity norms is critical for dental attention in general. The correct management of the photopolymerization devices avoids adverse effects related to cross-contamination as well as the level of preventive or restore treatments.

In the present study, significant differences in light intensity were observed in three photocuration lamps when comparing the application of physical protection barriers. Al-Marzok [20] found similar results when evaluating the relationship of two translucid barriers use with the hardness of its curated resin. Cellophane wrap presented the lower 
light intensity decrease in comparison to commercial disposable plastic. However, the study does not indicate significant differences in Knoop hardness values for both analyzed groups.

Khode [18] compared the light intensity reduction in several protection barriers with the microhardness of the resin. They point out that all the barriers effectively decrease the intensity and only one barrier of commercial availability and fragments of latex globes decreased the microhardness.

Likewise, Ajaj [21] compared both the effect of using infection control barriers and time exposure with the light intensity emitted. While a significant decrease in light intensity was observed, it does not differ with exposure times.

In another study, it has been demonstrated that the use of barriers and wrapping plastic reduced the light intensity significantly but without impact on the dental curation or negative effects at the clinical level [23].

Rueggeberg [1] indicates that most of the wrapping plastic barriers are not standardized and interfere with light intensity up to $40 \%$, while recommends to not allocate the cover unions over the light guide, which will reduce even more the light output.

In contrast, McAndrew [24] has not found differences between the use of commercial covers and wrapping plastic, while using globes or matt barriers can present reductions in the light intensity.

\section{Conclusion}

The use of translucid physical barriers over the light guide reduces significantly the light intensity emitted by the devices analyzed in this research. However, nowadays, its use is remarkably important to prevent any kind of crosscontamination between the device and the oral tissues. When using these barriers, it is recommended to monitoring continuously the light intensity to avoid the use of devices with critical intensities $\left(<400 \mathrm{~mW} \mathrm{C}^{*} \mathrm{~cm}-2\right)$ that can affect the curate of the restoring material.

\section{Compliance with ethical standards}

\section{Acknowledgments}

The authors thanks to all the people who motivated us and helped us with the research.

Disclosure of conflict of interest

The authors declare that they have no known competing financial interests or personal relationships that could have appeared to influence the work reported in this paper.

\section{References}

[1] Rueggeberg F. A., Giannini M., Arrais C. A. G., and Price R. B. T., "Light curing in dentistry and clinical implications: a literature review," Braz. Oral Res., vol. 31, no. suppl 1, pp. 64-91, Aug. 2017, doi: 10.1590/1807-3107bor2017.vol31.0061.

[2] Alqabbaa L., Alsenani M., Alsaif N., Alsaif R., and Binalrimal S., "Light intensity output of visible light communication units and clinicians' knowledge and attitude among Riyadh private clinics," J. Conserv. Dent., vol. 21, no. 6, p. 667, 2018, doi: 10.4103/JCD.JCD_252_18.

[3] Alonso R. C. B., Brandt W. C., Souza-Junior E. J. C., Puppin-Rontani R. M., and Sinhoreti M. A. C., "Photoinitiator concentration and modulated photoactivation: influence on polymerization characteristics of experimental composites," Appl. Adhes. Sci., vol. 2, no. 1, pp. 1-11, 2014, doi: 10.1186/2196-4351-2-10.

[4] Cadenaro M., Maravic, T., Comba, A., Mazzoni, A., Fanfoni, L., Hilton, T., Ferracane, J., \& Breschi, L., “The role of polymerization in adhesive dentistry," Dent. Mater., vol. 35, no. 1, pp. e1-e22, 2019, doi: 10.1016/j.dental.2018.11.012.

[5] Harlow J. E., Sullivan B., Shortall A. C., Labrie D., and Price R. B., "Characterizing the output settings of dental 
curing lights," J. Dent., vol. 44, pp. 20-26, Jan. 2016, doi: 10.1016/j.jdent.2015.10.019.

[6] Magalhães Filho T. R., Weig K. M., Costa M. F., Werneck M. M., Barthem R. B., and Costa Neto C. A., "Effect of LEDLCU light irradiance distribution on mechanical properties of resin based materials," Mater. Sci. Eng. C, vol. 63, pp. 301-307, 2016, doi: 10.1016/j.msec.2016.02.060.

[7] Mouhat M., Mercer J., Stangvaltaite L., and Örtengren U., "Light-curing units used in dentistry: factors associated with heat development_-potential risk for patients," Clin. Oral Investig., vol. 21, no. 5, pp. 1687-1696, 2017, doi: 10.1007/s00784-016-1962-5.

[8] Price R. B., Ferracane J. L., and Shortall A. C., "Light-Curing Units: A Review of What We Need to Know," J. Dent. Res., vol. 94, no. 9, pp. 1179-1186, Sep. 2015, doi: 10.1177/0022034515594786.

[9] Price R. B. T., "Light Curing in Dentistry," Dent. Clin. North Am., vol. 61, no. 4, pp. 751-778, Oct. 2017, doi: 10.1016/j.cden.2017.06.008.

[10] Rueggeberg F. A., Caughman W. F., and Comer R. W., "The effect of autoclaving on energy transmission through light-curing tips," J. Am. Dent. Assoc., vol. 127, no. 8, pp. 1183-1187, 1996, doi: 10.14219/jada.archive.1996.0409.

[11] Martin F. E., "A survey of the efficiency of visible light curing units," J. Dent., vol. 26, no. 3, pp. 239-243, 1998, doi: 10.1016/S0300-5712(97)00004-3.

[12] Elhejazi A. A., "The effects of temperature and light intensity on the polymerization shrinkage of light-cured composite filling materials," J. Contemp. Dent. Pract., vol. 7, no. 3, p. 12-21, Jul. 2006, [Online]. Available: http://europepmc.org/abstract/MED/16820803.

[13] Ernst, C.-P., Price, R. B., Callaway, A., Masek, A., Schwarm, H., Rullmann, I., Willershausen, B., \& Ehlers, V. , “Visible Light Curing Devices - Irradiance and Use in 302 German Dental Offices.," J. Adhes. Dent., vol. 20, no. 1, pp. 4155, 2018, doi: 10.3290/j.jad.a39881.

[14] Sword, R. J., Do, U. N., Chang, J. H., \& Rueggeberg, F. A., “Effect of Curing Light Barriers and Light Types on Radiant Exposure and Composite Conversion," J. Esthet. Restor. Dent., vol. 28, no. 1, pp. 29-42, Jan. 2016, doi: $10.1111 /$ jerd.12173.

[15] Hwang, I. N., Hong, S. O., Lee, B. N., Hwang, Y. C., Oh, W. M., \& Chang, H. S., "Effect of a multi-layer infection control barrier on the micro-hardness of a composite resin," J. Appl. Oral Sci., vol. 20, no. 5, pp. 576-580, 2012, doi: $10.1590 / \mathrm{S} 1678-77572012000500014$

[16] Caughman, G. B., Caughman, W. F., Napier, N., \& Schuster, G. S., “Disinfection of visible-light-curing devices.,” Oper. Dent., vol. 14, no. 1, pp. 2-7, 1989.

[17] Center for Diseases Control, "Recommendations from the Guidelines for Infection Control in Dental Health-Care Settings - 2003," Centers Dis. Control Prev., p. 17, 2003, [Online]. Available: http://www.cdc.gov/mmwr/PDF/\%0Ahttps://www.cdc.gov/oralhealth/infectioncontrol/pdf/recommendati ons-excerpt.pdf.

[18] Khode, R., Shenoi, P., Kubde, R., Makade, C., Wadekar, K., \& Khode, P., "Evaluation of effect of different disposable infection control barriers on light intensity of light-curing unit and microhardness of composite - An in vitro study," J. Conserv. Dent., vol. 20, no. 3, p. 180, 2017, doi: 10.4103/JCD.JCD_171_16.

[19] Celerino de Moraes Porto, I., Ramos de Brito, A., \& Parolia, A., "Effect of cross infection control barriers used on the light-curing device tips on the cure depth of a resin composite," J. Conserv. Dent., vol. 16, no. 3, p. 224, 2013, doi: 10.4103/0972-0707.111319.

[20] Al-Marzok, M., "The effect of wrapping of light-cure tips on the cure of composite resin," Eur. J. Gen. Dent., vol. 1, no. 3, p. 183, 2012, doi: 10.4103/2278-9626.105384.

[21] Ajaj, R., Nassar, H., \& Hasanain, F., "Infection control barrier and curing time as factors affecting the irradiance of light-cure units," J. Int. Soc. Prev. Community Dent., vol. 8, no. 6, p. 523, 2018, doi: 
10.4103/jispcd.JISPCD_226_18.

[22] Scott, B. A., Felix, C. A., \& Price, R. B. T., "Effect of disposable infection control barriers on light output from dental curing lights," J. Can. Dent. Assoc. (Tor)., vol. 70, no. 2, pp. 105-110, 2004.

[23] Hodson, N. A., Dunne, S. M., \& Pankhurst, C. L., "The Effect of Infection-Control Barriers on the Light Intensity of Light-Cure Units and Depth of Cure of Composite," Prim. Dent. Care, vol. 12, no. 2, pp. 61-67, Apr. 2005, doi: $10.1308 / 1355761053695149$.

[24] McAndrew, R., Lynch, C. D., Pavli, M., Bannon, A., \& Milward, P., "The effect of disposable infection control barriers and physical damage on the power output of light curing units and light curing tips," Br. Dent. J., vol. 210, no. 8, pp. 1-4, 2011, doi: 10.1038/sj.bdj.2011.312.

\section{Author's short biography}

Fernando Mauricio Villalta Mendoza
General Dentistry Faculty of Dentistry, University of Cuenca - Ecuador.
Student in Master's Degree in Didactics in Health Sciences, University Anáhuac, México.
General Dentistry Faculty of Dentistry, University of Cuenca - Ecuador.
Student in Master's Degree in Didactics in Health Sciences, University Anáhuac, México.
Yulissa Raquel Abad Salinas
General Dentistry Faculty of Dentistry, University of Cuenca - Ecuador.
Specialist in oral rehabilitation, University of Chile- Chile. Associate Professor of Faculty of Dentistry,
University of Cuenca.

